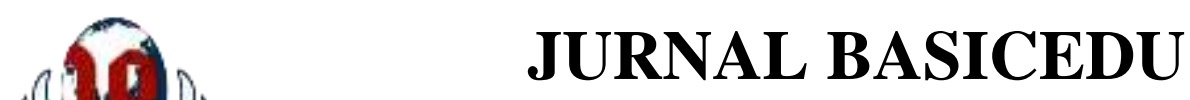

Volume 5 Nomor 6 Tahun 2021 Halaman 5827 - 5833

Research \& Learning in Elementary Education https://jbasic.org/index.php/basicedu

\title{
Evaluasi Penggunaan Aplikasi Distance Learning (Google Classroom) pada Orang Tua Siswa SD
}

\author{
Hanikah $^{1 凶}$, Hema Widiawati ${ }^{2}$, M. Rahmat ${ }^{3}$ \\ Universitas Muhammadiyah Cirebon, Indonesia ${ }^{1,2,3}$ \\ E-mail: hanikah@umc.ac.id ${ }^{1}$, hema.widiawati@umc.ac.id ${ }^{2}$, rahmat.zueng@gmail.com³
}

\begin{abstract}
Abstrak
Media adalah segala sesuatu yang dapat digunakan dalam mendukung pembelajaran online. Sebagaian besar sekolah yang berada di kabupaten Cirebon khususnya seolah dasar menggunakan aplikasi online jarak jauh berupa google classroom. Penelitian ini menggunakan pendekatan kualitatif dengan metode desktriptip analitis. Tujuannya adalah untuk mengeksplorasi pengetahuan orang tua siswa di SDN 1 Cipeujeuh Kulon terkait dengan media teknologi. Hasil penelitian menunjukkan, pemahaman orang tua siswa terkait penggunaan google classroom pada orang tua siswa di SDN 1 Cipeujeuh Kulon masih awam. Hal tersebut karena beberapa faktor, kurangnya pemahaman orang tua terkait teknologi, selain itu masih banyak orang tua yang mengabaikan arahan dari para guru untuk mendampingi proses kegiatan daring. Hal tersebut menjadi penyebab banyak siswa yang tidak mengerjakan tugas-tugas yang diberikan oleh guru. Idealnya guru perlu memberikan sosialisasi terkait penggunaan media google classroom agar orang tua siswa bisa secara maksimal dalam mendampingi proses pembelajaran yang dilakukan secara online. Dengan demikian dapat disimpulkan, penggunaan media teknologi google classroom mampu memberikan hal positif diantaranya, kedisiplinan, motivasi dan prestasi yang bisa meningkat.
\end{abstract}

Kata kunci: Pembelajaran online, google classroom, pemahaman orang tua.

\begin{abstract}
Media is anything that can be used to support online learning. Most schools in Cirebon district in particular seem to use a remote online application in the form of Google Classroom. This study uses a qualitative approach with an analytical descriptive method. The aim is to explore the knowledge of parents of students at SDN 1 Cipeujeuh Kulon related to technology media. The results showed, the understanding of parents regarding the use of google classroom for parents at SDN 1 Cipeujeuh Kulon is still common. This is due to several factors, the lack of understanding of parents regarding technology, besides that there are still many parents who ignore the directions from the teachers to accompany the process of online activities. This is the cause of many students who do not do the assignments given by the teacher. Ideally, teachers need to provide socialization related to the use of google classroom media so that parents can optimally accompany the online learning process. Thus it can be concluded, the use of Google Classroom technology media is able to provide positive things including, discipline, motivation and achievement that can increase.
\end{abstract}

Keywords: Online learning, google classroom, understanding of parents.

Copyright (c) 2021 Hanikah, Hema Widiawati, M. Rahmat

Corresponding author :

Email : hanikah@umc.ac.id

DOI : https://doi.org/10.31004/basicedu.v5i6.1777

ISSN 2580-3735 (Media Cetak)

ISSN 2580-1147 (Media Online)

Jurnal Basicedu Vol 5 No 6 Tahun 2021

p-ISSN 2580-3735 e-ISSN 2580-1147 
5828 Evaluasi Penggunaan Aplikasi Distance Learning (Google Classroom) pada Orang Tua Siswa SD Hanikah, Hema Widiawati, M. Rahmat

DOI: https://doi.org/10.31004/basicedu.v5i6.1777

\section{PENDAHULUAN}

Perkembangan teknologi yang dibawa era globalisasi perlahan tapi pasti mempengaruhi pola pemikiran, tatanan nilai, karakter dan budaya baik dalam lingkup masyarakat maupun individu (Fikriyah \& Faiz, 2019). Terutama dalam bidang teknologi dalam pemenuhan kebutuhan sehari-hari. Hasil survei Asosiasi Penyelenggara Jasa Internet Indonesia (APJII) periode 2019-kuartal II/2020 mencatat, jumlah pengguna internet di Indonesia mencapai 196,7 juta jiwa. Jumlah ini meningkat 23,5 juta atau 8,9\% dibandingkan tahun sebelumnya (Febrian Khoirulinsan, 2021).

Pandemi Covid-19 yang terus meluas di Indonesia mendorong pemerintah memberlakukan kebijakan bekerja dari rumah (work from home) dan belajar dari rumah untuk sementara waktu. Kemdikbud melalui surat edarannya menerangkan bahwa untuk menanggapi penyebaran Covid-19 yang semakin meningkat maka dihimbau untuk melaksanakan pembelajaran dari rumah melalui pembelajaran jarak jauh (PJJ) (Kemdikbud, 2020). Himbuan berupa surat edaran tersebut menegaskan bahwa pelaksanaan proses pembelajaran bagi siswa sekolah selama masa pandemi Covid-19 harus mengalami perubahan. Perubahan utamanya pada pembelajaran, dimana guru harus menggunakan pembelajaran jarak jauh (Lindawati, Y. I., \& Rahman, 2020). Kegiatan belajar mengajar selama ini dilakukan oleh guru dan siswa dalam ruang kelas di sekolah melalui interaksi tatap muka secara langsung, sedangkan pada masa pandemi Covid-19 keberadaan guru dan siswa terpisah secara fisik sebab masing-masing harus berada di rumah. Hal tersebut mengakibatkan guru dan siswa yang terbiasa berinteraksi secara langsung ketika membahas materi pelajaran dan tugas harus berganti melalui media komunikasi sebagai perantara interaksi diantara mereka. Kebiasaan baru ini tentu membutuhkan proses adaptasi untuk penyesuaian diri.

Sebagaian besar sekolah yang berada di kabupaten Cirebon khususnya seolah dasar menggunakan aplikasi online jarak jauh berupa google classroom. Google classroom adalah platform pembelajaran campuran yang dikembangkan oleh google untuk sekolah yang bertujuan menyederhanakan pembuatan, pendistribusian dan penetapan tugas dengan cara tanpa kertas (Wikipedia, 2017). Pemanfaatan google classroom dapat melalui multiplat form yakni melalui komputer dan telepon genggam. Guru dan siswa dapat mengunjungi situs https://classroom.google.com atau mengunduh aplikasi melalui playstore di android atau app store di IOS dengan kata kunci google classroom. Kegiatan belajar-mengajar jarak jauh yang dilakukan oleh para siswa masih terkendala kondisi sebagian Orang tua siswa khususnya pada siswa sekolah dasar kelas rendah, dimana mereka butuh bimbingan di dalam pembelajaran terutama dalam pengoprasian media pembelajaran yang bersipat online.

Pemanfaatan media saat ini menjadi keniscayaan. Media adalah segala sesuatu yang dapat digunakan dalam mendukung tersalurkannya sebuah pesan atau informasi dari pengirim ke penerima lainnya yang dapat merangsang pikiran, perasaan, perhatian dan minat siswa sehingga terjadi proses belajar. Sedangkan pengertian pembelajaran online menurut Dabbagh \& Ritland. B., (2005) adalah suatu sistem belajar yang bersifat terbuka dan tersebar dengan bantuan perangkat pendagogi (alat bantu pendidikan) yang tersambung melalui internet dan teknologi jaringan sehingga memungkinkan terbentuknya suatu pengetahuan serta terjadinya proses belajar. Penggunaan media pembelajaran online memiliki kelebihan yang memungkinkan terjadinya pembelajaran yang bersifat mandiri, interaktivitas yang tinggi, meningkatkan kualitas ingatan serta banyaknya pengalaman belajar karena pembelajarannya menggunakan teks, audio, video dan animasi yang cenderung memberikan kemudahan dalam aspek proses penyampaian materi, mengunduh, memperbarui, pengiriman email, komentar dan pertanyaan pada saat diskusi di ruang chat maupun video conference untuk berkomunikasi secara langsung (Dryden, 2001).

Dabbagh \& Ritland. B., (2005) menyebutkan bahwa pembelajaran online memiliki tiga komponen yaitu: 1.Model pembelajaran 2.Strategi instruksional dan pembelajaran 3.Media pembelajaran online Keterkaitan interaktif akan terbentuk dengan adanya ketiga komponen ini. Model pembelajaran yang tersusun 
5829 Evaluasi Penggunaan Aplikasi Distance Learning (Google Classroom) pada Orang Tua Siswa SD Hanikah, Hema Widiawati, M. Rahmat

DOI: https://doi.org/10.31004/basicedu.v5i6.1777

akan berfungsi sebagai suatu proses sosial yang memungkinkan tersampaikannya suatu informasi dengan desain yang sesuai dengan lingkungan pembelajaran online yang kemudian nantinya akan terarahkan pada spesifikasi strategi instruksional dan pembelajaran. Kondisi ini akan memungkinkan terjadinya kemudahan dalam belajar melalui pemanfaatan teknologi. Atsani (2020) menyatakan bahwa terdapat beberapa media pembelajaran online yang dapat dijadikan sebagai pilihan yaitu sebagai berikut: a) media pembelajaran online yang pertama dan yang paling sering digunakan adalah whatsapp group; b) media pembelajaran online yang berasal dari google adalah google suite for education; c) Media pembelajaran online selanjutnya adalah ruang guru; d) media pembelajaran online berikutnya adalah zenius; e) Media pembelajaran online berbasis video conference yang juga sering digunakan adalah zoom dan google meeting.

Dengan demikian pentingnya penggunaan media aplikasi googgle classroom dimasa pandemi sangat membantu guru dalam melaksanakan pembelajaran online. Namun perlu dipertegas kembali sejauh mana pemahaman orang tua siswa di SDN 1 Cipejeuh Kulon dalam mendampingi siswa saat belajar dari rumah menggunakan media aplikasi google classroom. Hal tersebut bertujuan untuk mengukur tingkat pemahaman dan kepedulian orang tua dalam mendampingi siswa saat pembelajaran online/ belajar dari rumah.

\section{METODE}

Penelitian ini dilakukan di SDN 1 Cipejeuh Kulon dengan waktu penelitian selama satu minggu. Penelitian ini menggunakan pendekatan kualitatif dengan metode deskriptif. Tujuannya adalah untuk mengeksplorasi pengetahuan orang tua siswa terkait dengan media teknologi. Adapun teknik pengumpulan data dengan cara observasi, wawancara dan pengisian kuisioner kepada 22 subjek penelitian yang terdiri dari orang tua siswa di SDN 1 Cipeujeuh Kulon. Wawancara dan pengisian kuisioner untuk mempertegas pemahaman para orang tua siswa terkait konsep dan penggunaan google scholar. Adapun data yang telah terkumpul disajikan dan direduksi untuk menganalisis data apa saja yang benar-benar dibutuhkan dalam penelitian ini. Data yang sudah direduksi kemudian di simpulkan. Namun sebelum ditarik kesimpulan data di koreksi dan di cocokkan dengan teknik triangulasi. Setelah dilakukan pencocokan data melalui triangulasi data maka hasil pengamatan dideskripsikan dalam bentuk kata-kata dan bahasa pada suatu konteks khusus dengan memanfaatkan metode yang alamiah (Sugiyono, 2012; Faiz \& Soleh, 2021).

\section{HASIL DAN PEMBAHASAN}

Dampak teknologi di era globalisasi ini mulai terasa manfaatnya saat terjadi pandemi Covid-19 yang mengharuskan manusia menghentikan aktivitasnya diluar rumah sementara dan memanfaatkan teknologi untuk melakukan interaksi dengan orang lain. Salah satu pemanfaatan kemajuan teknologi ini juga banyak diterapkan dalam dunia pendidikan (Faiz, 2021). Selain pemanfaatan teknologi. Peran orang tua kembali dimaksimalkan untuk mendampingi anak saat belajar dari rumah. Adanya kebijakan dari pemerintah terkait memaksimalkan aktivitas kegiatan di rumah juga semakin memurnikan dan menguatkan kembali peran keluarga dalam bidang pendidikan. Orangtua memiliki peran penting dalam mendidik anak, memberiksn keterampilan kognitif, edukasi kesehatan mental dan fisik, serta peningkatan kualitas kesehatan psikologis keluarga (Yulianingsih, Suhanadji, Nugroho, \& Mustakim, 2020). Selain itu, penelitian yang dilakukan oleh (Adawiyah, Faiz, \& Rahayu, 2021) menunjukkan orangtua berperan penting dalam menumbuhkan minat belajar siswa. Peran orang tua yang baik dapat menumbuhkan minat belajar yang baik pula.

Google Classroom menjadi salah satu media teknologi yang digunakan oleh dunia pendidikan dalam melaksanakan proses pembelajaran sebagaimana penelitian yang dilakukan oleh (Sutia \& Sagita, 2020). Google clasroom dirancang untuk membantu pengajar membuat dan mengumpulkan tugas tanpa kertas, termasuk fitur yang menghemat waktu seperti kemampuan untuk membuat salinan dokumen secara otomatis 
5830 Evaluasi Penggunaan Aplikasi Distance Learning (Google Classroom) pada Orang Tua Siswa SD Hanikah, Hema Widiawati, M. Rahmat

DOI: https://doi.org/10.31004/basicedu.v5i6.1777

bagi setiap siswa. Kelas elektronik ini juga dapat membuat folder penyimpanan untuk setiap tugas dan setiap siswa, agar semuanya tetap teratur. Siswa dapat melacak setiap tugas yang hampir mendekati batas waktu pengumpulan di halaman tugas, dan mulai mengerjakannya cukup dengan satu klik. Pengajar dapat melihat dengan cepat siapa saja yang belum menyelesaikan tugas, serta memberikan masukan dan nilai langsung di kelas elektronik. Untuk memahami sejauh mana tingkat pemahaman orang tua siswa dalam mendampingi siswa selama pembelajaran daring menggunakan google classroom maka peneliti melakukan pengukuran terkait pemahaman orang tua siswa/ wali murid.

\section{Pengukuran pemahaman orang tua siswa}

Untuk melihat sejauh mana pemahaman siswa terkait penggunaan google classroom maka peneliti melakukan proses evaluasi. Proses evaluasi ini menunjukkan seberapa paham orang tua melakukan pendampingan menggunakan media google classroom.

Tabel 1. Hasil Formulir Evaluasi

\begin{tabular}{|c|c|c|c|c|c|c|c|c|c|}
\hline \multirow{2}{*}{ No } & \multirow{2}{*}{ Pertanyaan } & \multicolumn{4}{|c|}{ Skala } & \multicolumn{4}{|c|}{ Persentasi \% } \\
\hline & & 1 & 2 & 3 & 4 & 1 & 2 & 3 & 4 \\
\hline 1 & $\begin{array}{l}\text { Apakah anda pernah mendengar istilah Google } \\
\text { class Room? }\end{array}$ & & 22 & & & & 100 & & \\
\hline 2 & Apakah anda memiliki akun Email atau Gmail? & & 10 & 12 & & & 45,5 & 54,5 & \\
\hline 3 & $\begin{array}{l}\text { Apakah anda pernah menggunakan aplikasi } \\
\text { Google class Room? }\end{array}$ & & 22 & & & & 100 & & \\
\hline 4 & $\begin{array}{l}\text { Apakah anda pernah menggunakan situs web } \\
\text { berbasis media pembelajaran online lainnya? }\end{array}$ & & 18 & 4 & & & 81,8 & 18,2 & \\
\hline 5 & $\begin{array}{l}\text { Pernahkah anda mencoba mengaplikasikan } \\
\text { Google Classroom? }\end{array}$ & & 14 & 8 & & & 63,6 & 36,4 & \\
\hline 6 & $\begin{array}{l}\text { Pernahkah anda melihat tampilan Google class } \\
\text { Room? }\end{array}$ & & & 22 & & & & 100 & \\
\hline 7 & $\begin{array}{lccr}\text { Bersediakah anda } & \text { menggunakan } & \text { media } \\
\text { pembelajaran dengan } & \text { menggunakan } & \text { Google } \\
\text { Classroom untuk digunakan di sekolah? } & \\
\end{array}$ & & & & 22 & & & & 100 \\
\hline
\end{tabular}

Keterangan:

1. Tidak setuju

2. Ragu-ragu

3. Setuju

4. Sangat setuju

Berdasarkan pada tabel diatas mengungkapkan bahwa pemahaman orang tua siswa terkait penggunaan google classroom pada orang tua siswa di SDN 1 Cipeujeuh Kulon masih awam. Hal tersebut karena beberapa faktor, kurangnya pemahaman orang tua terkait teknologi, selain itu masih banyak orang tua yang mengabaikan arahan dari para guru untuk mendampingi proses kegiatan daring. Hal tersebut menjadi penyebab banyak siswa yang tidak mengerjakan tugas-tugas yang diberikan oleh guru. Idealnya guru perlu memberikan sosialisasi terkait penggunaan media google classroom agar orang tua siswa bisa secara maksimal dalam mendampingi proses pembelajaran yang dilakukan secara online. Karena tak jarang kondisi pembelajaran online mengakibatkan siswa menjadi jenuh dalam belajar sebagaimana hasil penelitian (Hanina, Faiz, \& Yuningsih, 2021) salah satu contoh kejenuhan belajar yang dirasakan oleh peserta didik dalam pembelajaran online karena lingkungan belajar yang tidak mendukung saat pembelajaran berlangsung atau kurangnya bimbingan dari orang tua dan keluarga peserta didik tersebut. 
5831 Evaluasi Penggunaan Aplikasi Distance Learning (Google Classroom) pada Orang Tua Siswa SD Hanikah, Hema Widiawati, M. Rahmat

DOI: https://doi.org/10.31004/basicedu.v5i6.1777

Dari data tersebut hal yang perlu diperhatikan ketika menggunakan google classroom, guru sebaiknya memberi pemahaman kepada wali murid agar tidak terjadi kesalahpahaman dalam pelaksanaannya. Memberi pelatihan kepada siswa tentang penggunaan google classroom sebagai bentuk tahap pengenalan fungsi dan manfaat perangkat lunak tersebut. Tidak menutup kemungkinan jika diterapkan pertama kali mengalami kegagalan, diperlukannya refleksi dan monitoring dalam penyelenggaraan blended learning melalui google classroom (Wicaksono \& Rachmadyanti, 2016).

Perlu kita yakini bahwa google classroom menjadi media teknologi yang sangat populer digunakan selama pandemi covid-19. Sebagaimana diungkapkan Hapsari \& Pamungkas (2019) bahwa google classroom menjadi teknologi komunikasi paling utama dalam kegiatan proses pembelajaran. Kehebatan teknologi komunikasi ditandai dengan hadirnya metode pembelajaran e-learning. Google Classroom merupakan sarana memperlancar komunikasi jarak jauh antara pengajar dan mahasiswa terutama dalam kelas Pengelolan Konten Digital. Sarana belajar bersama, menerima dan membaca materi, mengirimkan tugas secara jarak jauh hingga menyajikan nilai tugas secara transparansi. Semua mahasiswa yang terlibat dalam proses pembelajaran ini mendapatkan kesempatan yang sama.

Pemanfaatan media google classroom juga memberikan peningkatan hasil daripada menggunakan metode pembelajaran ekspositori sebagaimana yang dilakukan oleh (Samosir, Salim Efendi, \& Imelda Gultom, 2020) pada mata pelajaran IPS. Selain itu pemanfataan pogram google classroom dapat meningkatkan motivasi belajar, dapat meningkatkan prestasi belajar sebagaimana hasil penelitian yang dilakukan oleh (Ali \& Zaini, 2020).

Dengan penggunaan aplikasi google classroom ini maka akan membantu mempermudah para pendidik maupun peserta didik dalam proses pembelajaran. Selain itu, aplikasi ini dapat membuat para siswa memiliki karakter yang disiplin dalam pengerjaaan dan pengumpulkan tugas dikarenakan pendidik dapat mengatur waktu pengumpulan tugas. Hal ini sangat baik untuk penanaman pembiasaan melalui tugas yang diberikan oleh guru melalui aplikasi google classroom (Faiz, Soleh, Kurniawaty, \& Purwati, 2021). Melalui metode dan proses pembelajaran ini dapat dilakukan dimana saja oleh pendidik dan peserta didik tanpa terbatas pada ruang kelas yang tersedia (Sukmawati, 2020). Namun di SDN 1 Cipejeuh Kulon peran orang tua dalam mendampingi siswa masih tergolong awam karena masih minim pengetahuan untuk penggunaan media aplikasi google classroom. Dengan demikian pentingnya memberikan edukasi kepada orang tua siswa terkait pemanfaatan media teknologi google classroom saat mendampingi siswa pembelajaran online.

\section{KESIMPULAN}

Pemahaman orang tua siswa terkait penggunaan google classroom pada orang tua siswa di SDN 1 Cipeujeuh Kulon masih awam. Hal tersebut karena beberapa faktor, kurangnya pemahaman orang tua terkait teknologi, selain itu masih banyak orang tua yang mengabaikan arahan dari para guru untuk mendampingi proses kegiatan daring. Hal tersebut menjadi penyebab banyak siswa yang tidak mengerjakan tugas-tugas yang diberikan oleh guru. Idealnya guru perlu memberikan sosialisasi terkait penggunaan media google classroom agar orang tua siswa bisa secara maksimal dalam mendampingi proses pembelajaran yang dilakukan secara online. Padahal menggunakan media teknologi google classroom diyakini mampu memberikan hal positif diantaranya, kedisiplinan, motivasi dan prestasi yang bisa meningkat. 
5832 Evaluasi Penggunaan Aplikasi Distance Learning (Google Classroom) pada Orang Tua Siswa SD Hanikah, Hema Widiawati, M. Rahmat

DOI: https://doi.org/10.31004/basicedu.v5i6.1777

\section{DAFTAR PUSTAKA}

Adawiyah, R., Faiz, Aiman, \& Rahayu, Fanny Septiany. (2021). PERAN ORANGTUA DALAM MENUMBUHKAN MINAT BELAJAR SISWA SD (Studi Kasus Di Kelurahan Argasunya Yang Memiliki Angka Siswa Putus Sekolah Yang .... Jurnal Kreatif: Jurnal Kependidikan Dasar, 115-119. Retrieved From Https://Journal.Unnes.Ac.Id/Nju/Index.Php/Kreatif/Article/View/27831

Ali, Lalu Usman, \& Zaini, Muhammad. (2020). Pemanfaatan Program Aplikasi Google Classroom Sebagai Upaya Meningkatkan Motivasi Dan Prestasi Belajar Mahasiswa Pada Perkuliahan Dasar-Dasar Kependidikan. Society, 11(1), 27-34. Https://Doi.Org/10.20414/Society.V11i1.2297

Dabbagh, N., \& Ritland. B. (2005). Online Learning: Concepts, Strategies And Application. Ohio: Pearson.

Dryden, Gordon And Vos. J. (2001). Revolusi Cara Belajar. Bandung: Kaifa.

Faiz, Aiman. (2021). PERAN FILSAFAT PROGRESIVISME DALAM MENGEMBANGKAN KEMAMPUAN CALON PENDIDIK DI ABAD-21. Jurnal Education And Development Institut Pendidikan Tapanuli Selatan, 9(1), 131-135.

Faiz, Aiman, \& Soleh, B. (2021). Implementasi Pendidikan Karakter Berbasis Kearifan Lokal. Jinop (Jurnal Inovasi Pembelajaran), 7(1), 68-77. Https://Doi.Org/10.22219/Jinop.V7i1.14250

Faiz, Aiman, Soleh, Bukhori, Kurniawaty, Imas, \& Purwati. (2021). Tinjauan Analisis Kritis Terhadap Faktor Penghambat Pendidikan Karakter Di Indonesia. Jurnal Basicedu, Volume 5(4), 1766-1777. Https://Doi.Org/Https://Doi.Org/10.31004/Basicedu.V5i4.1014

Febrian Khoirulinsan. (2021). Urgensi Literasi Digital Dalam Kehidupan Bermasyarakat.

Fikriyah, F., \& Faiz, A. (2019). Penanaman Karakter Melalui Peran Pendidik Dalam Menghadapi Tantangan Di Era Globalisasi. Jurnal PGSD, 5(2). Retrieved From Https://EJournal.Umc.Ac.Id/Index.Php/JPS/Article/View/744

Hanina, Putri, Faiz, Aiman, \& Yuningsih, Dewi. (2021). Upaya Guru Dalam Mengatasi Kejenuhan Belajar Peserta Didik Di Masa Pandemi. Basicedu, 5(5), 3791-3798. Retrieved From Https://Doi.Org/10.31004/Basicedu.V5i5.1402

Hapsari, Swita Amallia, \& Pamungkas, Heri. (2019). Pemanfaatan Google Classroom Sebagai Media Pembelajaran Online Di Universitas Dian Nuswantoro. WACANA: Jurnal Ilmiah Ilmu Komunikasi, 18(2), 225-233. Https://Doi.Org/10.32509/Wacana.V18i2.924

Kemdikbud. (2020). Pembelajaran Secara Daring Dan Bekerja Dari Rumah Untuk Mencegah Penyebaran Covid 19.

Lindawati, Y. I., \& Rahman, C. A. (2020). Adaptasi Guru Dalam Implementasi Pembelajaran Daring Di Era Pandemi Covid-19. Prosiding Seminar Nasional Pendidikan FKIP. Serang: Universitas Sultang Ageng Tirtayasa.

Samosir, Alex, Salim Efendi, \& Imelda Gultom. (2020). Pengaruh Metode Pembelajaran Google Classroom Dengan Pola Asuh Orang Tua Terhadap Hasil Belajar Massa Covid- 19 Di Lubuk Pakam. Jurnal Tunas Bangsa, 7(2), 266-279. Https://Doi.Org/10.46244/Tunasbangsa.V7i2.1159

Sugiyono. (2012). Metode Penelitian Kuantitatif Kualitatif Dan R\&B. Bandung: CV. Alfabeta.

Sukmawati, Sukmawati. (2020). Implementasi Pemanfaatan Google Classroom Dalam Proses Pembelajaran Online Di Era Industri 4 . 0. Jurnal Kreatif Online, 8(1), 39-46. Retrieved From Http://Jurnal.Untad.Ac.Id/Jurnal/Index.Php/JKTO/Article/View/15680

Sutia, Cece, \& Sagita, Sylva. (2020). Tanggapan Siswa , Orang Tua Dan Guru Terhadap Pembelajaran Jarak Jauh Selama Pandemi Covid-19 Students , Parents And Teachers' Responses To Distance Learning During The Covid-19 Pandemic. Jurnal Inspirasi, 19(2), 156-165.

Wicaksono, Vicky Dwi, \& Rachmadyanti, Putri. (2016). Pembelajaran Blended Learning Melalui Google Classroom Di Sekolah Dasar. Seminar Nasional Pendidikan PGSD UMS \& HDPGSDI Wilayah Timur, 
5833 Evaluasi Penggunaan Aplikasi Distance Learning (Google Classroom) pada Orang Tua Siswa SD Hanikah, Hema Widiawati, M. Rahmat

DOI: https://doi.org/10.31004/basicedu.v5i6.1777

513-521. Retrieved From Http://Hdl.Handle.Net/11617/9144

Wikipedia. (2017). Google Classroom.

Yulianingsih, Wiwin, Suhanadji, Suhanadji, Nugroho, Rivo, \& Mustakim, Mustakim. (2020). Keterlibatan Orangtua Dalam Pendampingan Belajar Anak Selama Masa Pandemi Covid-19. Jurnal Obsesi : Jurnal Pendidikan Anak Usia Dini, 5(2), 1138-1150. Https://Doi.Org/10.31004/Obsesi.V5i2.740 